\title{
Purification and characterization of the cuticle-degrading proteases produced by an isolate of Beauveria bassiana using the cuticle of the predatory bug, Andrallus spinidens Fabricius (Hemiptera: Pentatomidae)
}

\author{
Hossein Firouzbakht ${ }^{1}$, Arash Zibaee ${ }^{1 *}$, Hassan Hoda ${ }^{2}$, Mohammad Mehdi Sohani ${ }^{3}$ \\ ${ }^{1}$ Department of Plant Protection, Faculty of Agricultural Sciences, University of Guilan, Rasht, 41635-1314 Iran \\ ${ }^{2}$ Biological Control Department, National Institute of Plant Protection, Amol, 91951-46191 Iran \\ ${ }^{3}$ Department of Agronomy and Plant Breeding, Faculty of Agricultural Sciences, University of Guilan, Rasht, 41635-1314 Iran
}

Received: November 26, 2014

Accepted: April 21, 2015

\begin{abstract}
The entomopathogenic fungi-like Beauveria bassiana must penetrate via the integument of an insect to reach the hemocoel. Since proteins are the molecules responsible for integument strength in insects, the proteins must synthesise the cuticle degrading proteases which will then enable the proteases to penetrate. It is important to determine the biochemical properties of these proteases so that fungal virulence can be better understood. In the current study, a recently collected isolate of $B$. bassiana, namely AM-118, was inoculated in liquid media containing $0.5 \%$ of Andrallus spinidens Fabricus cuticle to obtain specific proteases. The crude samples were purified via a three step process using ammonium sulfate, Sepharyl G-100, and DEAE-Cellulose Fast Flow. The results revealed two proteases known as subtilisin-like (Pr1), and trypsin-like (Pr2), with the molecular weights of 105 and $103 \mathrm{kDa}$. The optimal pH and temperature values were found to be 8 and $35^{\circ} \mathrm{C}$ for $\operatorname{Pr} 1$ and 8 and $40^{\circ} \mathrm{C}$ for Pr2, respectively. Inhibitors like AEBSF, EDTA, TPCK, and phenanthroline significantly affected proteolytic activities. Here, we reported two fungal proteases by high molecular weight from an Iranian isolate of B. bassiana. These findings will help us to better understand fungal virulence against insects.
\end{abstract}

Key words: Andrallus spinidens, Beauveria bassiana, protease, purification

\section{Introduction}

Entomopathogenic fungi belong to various orders, such as Zygomycota, Ascomycota, and Deuteromycota (Samson et al. 1988). These fungi are important components in modern agriculture as they are used as biocontrol agents against a wide range of agricultural pests (Rodgers 1989; Andreev et al. 2008). Entomopathogenic fungi are able to infect their hosts by passing through the integument. A mechanical or biochemical process is involved (Pucheta et al. 2006; Liu et al. 2009). Efficient virulence of the entomopathogenic fungi depends on the interactions between the host and the cell walls of the fungi (Liu et al. 2006). This is because the integument of insects is the first barrier against the germ tube of the entomopathogenic fungi as it tries to reach the hemolymph (Gillespie et al. 1998). Entomopathogenic fungi utilise two major proteases known as subtilisin-like serine protease (Pr1) and trypsin-like protease (Pr2) (St. Lager et al. 1986; Braga et al. 1999; Dias et al. 2008) to overcome this barrier. Several entomopathogenic fungi, such as: Beauveria bassiana, Metarhizium anisopliae, Lecanicilium lecanii, Numuraea rileyi, and Metarhizum flavoviride have demonstrated Pr1 and Pr2 activities (Bidochka and Meltzer 2000). During the initial stages of cuticle degradation, these proteases are secreted via a signal transduction mechanism by activation of the protein kinase A (PKA) mediated by antimicrobial peptides (AMPs) (Fang et al. 2009). It is believed that Pr1 is the key component in the penetration process since it is a virulent indicator for the entomopathogenic fungi (Castellanos-Moguel et al. 2007). The enzyme contains eleven isoforms. The molecular structure of the enzyme has five cysteines forming two disulfide bridges but another cysteine is found near the catalytic triad formed of Asp39, His69, and Ser224 (Liu et al. 2007).

The predatory bug, Andrallus spinidens Fabricius (Hemiptera: Pentatomidae), is a promising biocontrol agent of the Pyralidae and Noctuidae rice pest families. This predatory bug also has biocontrol potential against Chilo suppressalis Walker (Lepidoptera: Crambidae) (SorkhabiAbdolmaleki et al. 2013). It is necessary to consider the possible interactions of the biocontrol agents when they are to be used synchronologically against a pest. Since C. suppressalis have shown resistance to the chemical insecticide, diazinon, in several areas of northern Iran, biocontrol agents such as B. bassiana and A. spinidens seem to be appropriate candidates to efficiently and safely control the pest. Ramzi and Zibaee (2014) recently determined virulence of several entomopathogenic fungi, including 
B. bassiana, on the larvae of C. suppressalis. Understanding the potential adaptability of the two biocontrol agents is crucial to preventing conflicts in an agro-ecosystem. Therefore, we are interested in the virulence of two isolates of B. bassiana - BB2 and AM-118 - on A. spinidens (Safavi 2010; Chitgar et al. 2014; Firouzbakht et al. 2015). In this context, we have conducted the current study by extracting and purifying Pr1 and Pr2 proteases produced by isolate AM-118. The enzymes were purified via chromatography and their properties were investigated by considering $\mathrm{pH}$, temperature, and specific inhibitors. This is the first time that such a study has been carried out using the cuticle of a biocontrol agent.

\section{Materials and Methods}

\section{Beauveria bassiana culture}

Isolate AM-118 of B. bassiana was cultured at $25 \pm 1^{\circ} \mathrm{C}$ on Potato Dextrose Agar (PDA) (pH 5.6) supplemented with $1 \%$ yeast extract. After 14 days, conidia of the fungus were washed off using a $0.01 \%$ aqueous solution of Tween 20 . A concentration of $10^{7}$ spore $\cdot \mathrm{ml}^{-1}$ was prepared for the liquid culture medium.

\section{Culture and growth conditions}

The liquid culture medium used for protease production consisted of $\mathrm{CaCl}_{2}(0.01 \%), \mathrm{KH}_{2} \mathrm{PO}_{4}(0.02 \%), \mathrm{Na}_{2} \mathrm{HPO}_{4}$ $(0.02 \%), \mathrm{MgSO}_{4}(0.01 \%)$, and $\mathrm{ZnCl}_{2}(0.01 \%)$. The medium was inoculated with $10^{7}$ spores $\cdot \mathrm{ml}^{-1}$ of isolate AM-118 and $5 \mathrm{~g}$ of $A$. spinidens cuticle. Incubation took place for 8 days on a rotatory shaker $\left(120 \mathrm{rev} \cdot \mathrm{min}^{-1}\right)$ at $25 \pm 1^{\circ} \mathrm{C}$, in $300 \mathrm{ml}$ of Erlenmeyer flasks with a working volume of $100 \mathrm{ml}$ (Hajji et al. 2007). The flasks were sealed and shaked for the incubation period.

\section{Sample preparation}

Mycelia in the liquid media, were gathered by centrifugation at $8,000 \times \mathrm{g}$ for $15 \mathrm{~min}$ and ground to a fine powder. The powder was incubated in the lysis buffer $(1 \mathrm{mg}$ in $1 \mathrm{ml}$ of $25 \mathrm{mM}$ universal $\mathrm{pH} 8,10 \%$ [v/v] glycerol and $1 \mathrm{mM}$ EDTA) for $24 \mathrm{~h}$ and centrifuged at $12,000 \times \mathrm{g}$ for $15 \mathrm{~min}$. The given sample was stored at $-20^{\circ} \mathrm{C}$ and used for enzymatic assays (Dias et al. 2008).

\section{Proteolytic assays}

Subtilisin-like (Pr1) and trypsin-like (Pr2) activities in the isolate AM-118 were determined using succinyl-(alanine) 2-prolinephenylalanine- $p$-nitroanilide and benzoyl-phenylalanine-valinearginine- $p$-nitroanilide as substrates, respectively (Dias et al. 2008). Each assay consisted of $10 \mu \mathrm{l}$ of the substrate $(1 \mathrm{mM}), 40 \mu \mathrm{l}$ of $20 \mathrm{~mm}$ universal buffer ( $\mathrm{pH} 8$; and containing succinate, glycine, and 2-morpholinoethanesulfonic acid) (Frugoni 1957), and $5 \mu$ l of the enzyme. The mixture was incubated for $10 \mathrm{~min}$ at $25^{\circ} \mathrm{C}$ and the absorbance was read at $405 \mathrm{~nm}$. Activities were expressed as micromoles nitroanilide (NA) released per ml per min (St. Leger et al. 1998).

\section{Protease purification}

Purification of the proteases was based on a three-step procedure described by Hajji et al. (2007). The samples were initially precipitated with a $70 \%$ concentration of ammonium sulfate. The precipitated fraction was collected by centrifugation at $15,000 \mathrm{~g}$ prior to adding the universal buffer. Finally, the sample solution was subjected to dialysis tubing $(12,000 \mathrm{Da})$ for $20 \mathrm{~h}$. Then, the dialysed sample was subjected to gel filtration on a Sephacryl G-100 column equilibrated with a universal buffer. Enzyme fractions at $1 \mathrm{ml}$ were collected at a flow rate of $20 \mathrm{ml} \cdot \mathrm{h}^{-1}$ with the same buffer. Protein content and protease activities were measured separately, and the fractions showing the highest activities were pooled for the final step. The active fractions were applied to a DEAE-Cellulose Fast Flow equilibrated with universal buffer. After washing with the same buffer, bound proteins were eluted with a linear gradient of $\mathrm{NaCl}$ in the range of 0.1 to $0.5 \mathrm{~m}$. The fractions showing the highest proteolytic activities were pooled and stored at $-20^{\circ} \mathrm{C}$ for further analysis.

\section{Protein determination}

Protein concentrations were assayed according to the method described by Lowry et al. (1951). The method recruits reaction of $\mathrm{Cu}^{2+}$ produced by the oxidation of peptide bonds with Folin-Ciocalteu reagent. In the assay, $20 \mu \mathrm{l}$ of the homogenised sample was added to $100 \mu \mathrm{l}$ of reagent. Incubation was done for $30 \mathrm{~min}$ prior to reading the absorbance at $545 \mathrm{~nm}$ (as recommended by Ziest Chem. Co., Tehran-Iran).

\section{Polyacrylamide gel electrophoresis}

Sodium dodecyl sulphate polyacrylamide gel electrophoresis (SDS-PAGE) was carried out for the determination of the purity and molecular mass of the proteases, as described by Laemmli (1970), using a 5\% (w/v) stacking gel and a $10 \%(\mathrm{w} / \mathrm{v})$ separating gel. After loading the samples, electrophoresis was run at a voltage of $80 \mathrm{~V}$. At the end, the gel was separated from the glasses, washed with distilled water and incubated in a staining solution containing: water : acetic acid : ethanol $(4: 2: 1)$ and $0.2 \mathrm{~g}$ of Coomassie Brilliant Blue.

\section{Measurement of kinetic parameters}

Kinetic parameters of the purified proteases were evaluated using different concentrations of each substrate $(1,2$, $3,5,7$, and $10 \mathrm{mM}$ ). The reaction mixture was prepared using the above mentioned components and each substrate concentration. The given data was changed to specific activity. Finally the Michaelis constant $\left(K_{\mathrm{m}}\right)$ and the maximal velocity $\left(V_{\max }\right)$ were estimated using Sigmaplot software version 6 .

\section{Effect of $\mathrm{pH}$ and temperature on the activity of the enzyme}

The effects of temperature and $\mathrm{pH}$ on Pr1 and Pr2 activities were studied using specific substrates. The optimal 
$\mathrm{pH}$ was determined using universal buffer $(20 \mathrm{mM})$ with the $\mathrm{pH}$ set at $5-11$. The effect of temperature on protease activity was determined by incubating the reaction mixture at $20-50^{\circ} \mathrm{C}$.

\section{Effect of specific inhibitors on protease activity}

The effects of specific inhibitors on protease activity were studied using 4-(2-aminoethyl) benzenesulfonyl fluoride hydrochloride (AEBSF, $5 \mathrm{mM}$, as serine inhibitors), ethylenediaminetetraacetic acid (EDTA, $5 \mathrm{mM}$, as metallopropteinase inhibitor), tosyllysine chloromethyl ketone hydrochloride (TLCK, $5 \mathrm{mM}$, as trypsin inhibitor), tosyl phenylalanyl chloromethyl ketone (TPCK, $5 \mathrm{mM}$, as chymotrypsin inhibitor), and phenanthroline $(5 \mathrm{mM}$, as metallopropteinase inhibitor). The purified enzyme was preincubated with the inhibitors for $10 \mathrm{~min}$ at $30^{\circ} \mathrm{C}$.

\section{Statistical analysis}

All data were analysed by one-way analysis of variance (ANOVA) followed by Tukey's student test when significant differences were found at $\mathrm{p}<0.05$ (SAS 1997).

\section{Results and Discussion}

\section{Purification of proteases}

The virulence of an entomopathogenic fungi demonstrated as the percentage of mortality on a host. The efficient virulence highly depends on ability of a fungus to penetrate via integument. The penetration is a multi-complex processes in which both mechanical forces and relevant enzymes regarding the chemical composition of integument are crucial to facilitate fungal penetration. It is believed that proteases and esterases are the enzymes present in the first $24 \mathrm{~h}$ of fungal infestation (St. Leger et al. 1986). Since $80 \%$ of insect integument consists of proteins, the proteases play a prominent roles in the degradation process. As indicated earlier, penetration of entomopathogenic fungi via integument requires subtilisin-like serine protease Pr1 and trypsin-like enzyme Pr2. In the current study, the proteases produced by isolate AM-118 from $B$. bassiana were purified using the three-step procedure: ammonium sulfate precipitation, Sephacryl G-100, and DEAE-Cellulose Fast Flow chromatographies. After ammonium sulfate precipitation, the specific obtained activities of Pr1 and Pr2 were 13.3 and $22 \mathrm{U} \cdot \mathrm{mg}^{-1}$ protein; recovery (\%) for Pr1 and Pr2 was found to be 37.67 and 94.42\%; purification folds were 3.43 and 8.59 (Tables 1, 2). In Sephacryl G-100 chromatography, fractions 16-25 for Pr1 and 12-16 for Pr2 showed the highest proteolytic activities (Fig. 1).

Specific activities of the pooled fractions for the enzymes were found to be 17.72 and $32.27 \mathrm{U} \cdot \mathrm{mg}^{-1}$ protein (Tables 1, 2). Fractions 7-12 for Pr1 and 10-13 for Pr2 showed the highest activities (Fig. 1) in DEAE-Cellulose Fast Flow column. At the end of the purification process, Pr1 and Pr2 proteases showed specific activities of 72.30 and $114.61 \mathrm{U} \cdot \mathrm{mg}^{-1}$ protein, recovery of 26.62 and $63.94 \%$, and a purification fold of 18.68 and 44.86 , respectively (Tables 1, 2). Finally, SDS-PAGE of the samples showed a single band by 105 and $103 \mathrm{kDa}$ of molecular weights for Pr1 and Pr2, respectively (Fig. 2). Biodochka and Khachatourians (1987) found a molecular weight of $35 \mathrm{kDa}$ for a protease produced by B. bassiana. Pei et al. (2000) purified a protease by molecular weight of $27 \mathrm{kDa}$ produced by M. anisopliae. Zibaee and Bandani (2009) showed molecular weight of $47 \mathrm{kDa}$ in a purified protease produced by B. bassiana in the presence of Eurygaster integriceps Puton (Hemiptera: Scutelleridae). Lakshmi et al. (2010) reported the molecular weight of 19 and $21 \mathrm{kDa}$ for proteases produced by B. bassiana and M. anisopliae. In the current study, we collected an Iranian isolate of B. bassiana and extracted its protease using an A. spinidens cuticle. Species, media of production, and level of the fungal interaction by its host may affect molecular weight, isoforms and biochemical properties of the en-

Table 1. Purification parameters of Pr1 from isolate AM-118 of Beauveria bassiana

\begin{tabular}{|c|c|c|c|c|}
\hline Purification steps & $\begin{array}{c}\text { Unit activity } \\
{[\mathrm{U}]}\end{array}$ & $\begin{array}{l}\text { Specific activity } \\
{\left[\mathrm{U} \cdot \mathrm{mg}^{-1} \text { protein }\right]}\end{array}$ & $\begin{array}{c}\text { Recovery } \\
{[\%]}\end{array}$ & Purification fold \\
\hline Crude extract & 3.53 & 3.87 & 100.00 & 1.00 \\
\hline Ammonium sulfate $70 \%$ & 1.33 & 13.30 & 37.67 & 3.43 \\
\hline Sephacryl G-100 & 1.17 & 17.72 & 33.14 & 4.57 \\
\hline DEAE-Fast Flow & 0.94 & 72.30 & 26.62 & 18.68 \\
\hline
\end{tabular}

*all experiments have been carried out at $4^{\circ} \mathrm{C}$

Table 2. Purification parameters of Pr2 from isolate AM-118 of Beauveria bassiana

\begin{tabular}{lcccc}
\hline \multicolumn{1}{c}{ Purification steps } & Unit activity & \multicolumn{2}{c}{$\begin{array}{c}\text { Specific activity } \\
{\left[\mathrm{U} \cdot \mathrm{mg}^{-1} \text { protein] }\right.}\end{array}$} & \multicolumn{2}{c}{ Recovery } \\
{$[\%]$}
\end{tabular}

*all experiments have been carried out at $4^{\circ} \mathrm{C}$ 
Pr1-Sephacryl G-100

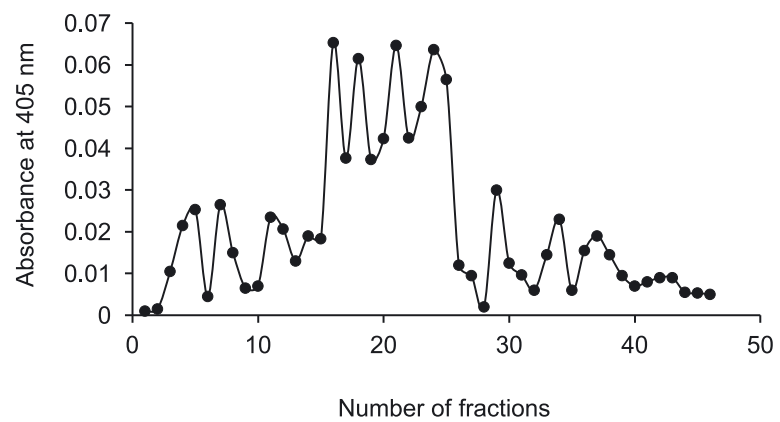

Pr1-DEAE Fast Flow

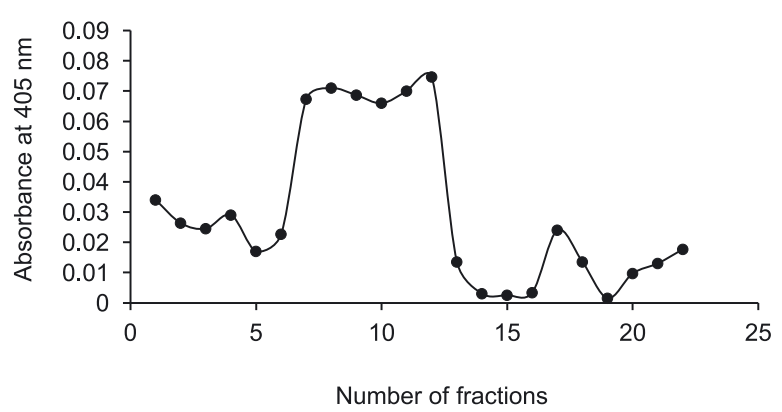

Pr2-Sephacryl G-100

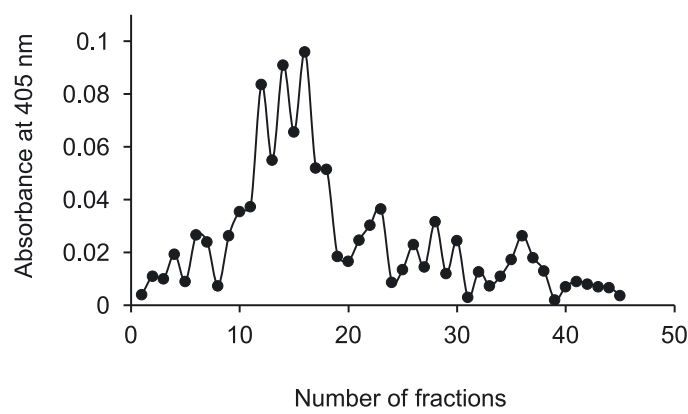

Pr2-DEAE Fast Flow

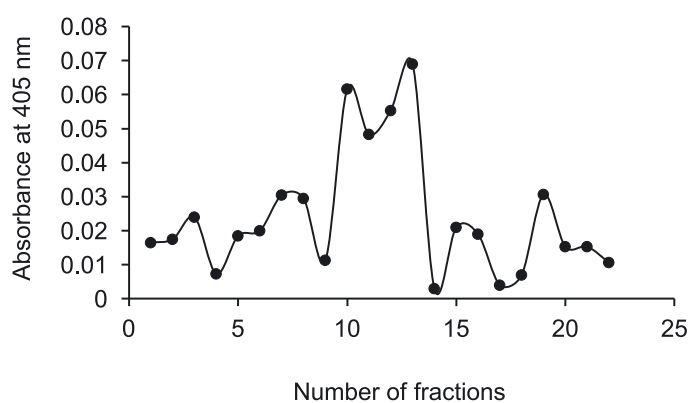

Fig. 1. Purification of Pr1 and Pr2 from isolate AM-118 of Beauveria bassiana via Sephacryl G-100 and DEAE-Fast Flow chromatographies

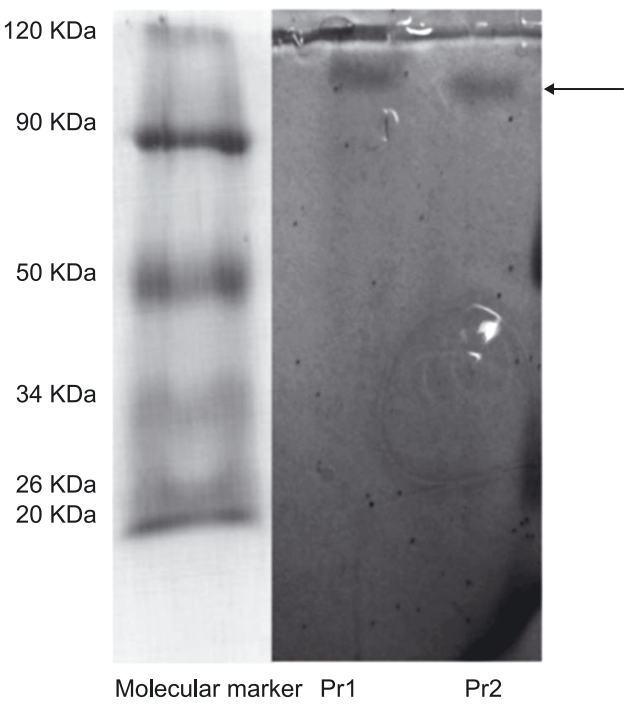

Fig. 2. SDS-PAGE showing purity and molecular weight of the proteases from isolate AM-118 of Beauveria bassiana

zymes produced by microorganisms. Since proteins may be in various structures, different isoforms of proteases were required to be digested. This diversity may cause some types of host-microbe interactions evolving enzyme secretions and their inhibitors.

\section{Kinetic parameters of proteases}

Kinetic parameters of the purified Pr1 and Pr2 were found as $V_{\max }$ values of 3.33 and $1.17 \mathrm{U} \cdot \mathrm{mg}^{-1}$ of protein, and $K_{\mathrm{m}}$ values of 0.7184 and $0.216 \mathrm{mM}$, respectively (Fig. 3).
Since Pr1 has a higher maximal velocity than Pr2, it may be that Pr1 has a higher efficiency for degrading the host's cuticle. On the other hand, Pr2 could cause a more stable complex with its substrate. The $K_{\mathrm{m}}$ has an inverse relationship with the substrate concentration, meaning that saturating the active sites of the enzyme is required. A high $K_{\mathrm{m}}$ would indicate weak binding and a low $K_{\mathrm{m}}$ would indicate strong binding. Hence, it was clearly depicted that Pr1 has stronger activity in comparison with Pr2 due to having a higher $V_{\max }$ and lower $K_{\mathrm{m}}$. Consequently, Pr1 is able to better degrade the insect cuticle to facilitate fungal penetration.

\section{Effect of $\mathrm{pH}$ and temperature on protease activity}

The effects of $\mathrm{pH}$ and temperature on Pr1 and Pr2 activities were determined using their specific substrates at various $\mathrm{pH}$ and temperature settings (Figs. 4, 5). An optimal $\mathrm{pH}$ of 8 was found for both proteases by specific activities of 149.08 and $305.19 \mathrm{U} \cdot \mathrm{mg}^{-1}$ protein, respectively. There was a slight, significant difference between the $\mathrm{pH}$ of 7 and 8 in the case of Pr2 (Fig. 4). As concerns the activity of the proteases, the optimal temperature values for Pr1 and Pr2 were 35 and $40^{\circ} \mathrm{C}$ for Pr1 and Pr2, with specific activities of 492.12 and $94.36 \mathrm{U} \cdot \mathrm{mg}^{-1}$ protein, respectively (Fig. 5). Bidochka and Khachatourians (1987) reported a $\mathrm{pH}$ value of 8.5 and a temperature of $37^{\circ} \mathrm{C}$ as the optimal values for proteolytic activity in B. bassiana. Moreover, Larcher et al. (1992) in Aspergillus fumigatus, Tunga et al. (2003) in A. parasiticus, Hajji et al. (2007) in A. clavatus, and Zibaee and Bandani (2009) in B. bassiana - showed optimal pHs of 8-9.5 and temperatures of $30-45^{\circ} \mathrm{C}$. Temperature could significantly affect the growth and sur- 


\section{AM-118/Protease}

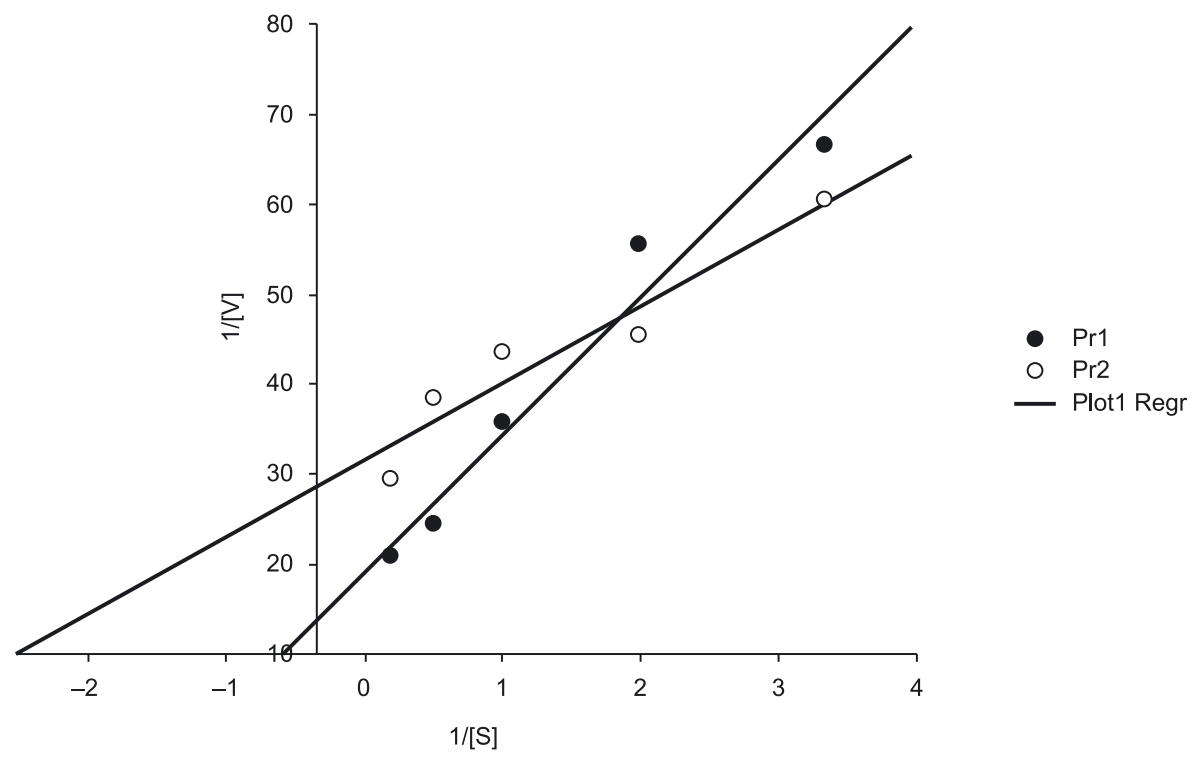

Fig. 3. Double reciprocal plot to show the kinetic parameters of the purified Pr1 and Pr2 from isolate AM-118 of Beauveria bassiana $\left(1 / V_{\max }-\right.$ intercept on the $1 / \mathrm{V} 0$ ordinate; $-1 / K_{\mathrm{m}}$ - intercept on the negative side of the $1 /[\mathrm{S}]$ abscissa). $\mathrm{R}^{2}$ for $\operatorname{Pr} 1$ is 0.85 and $\operatorname{Pr} 2$ is 0.91
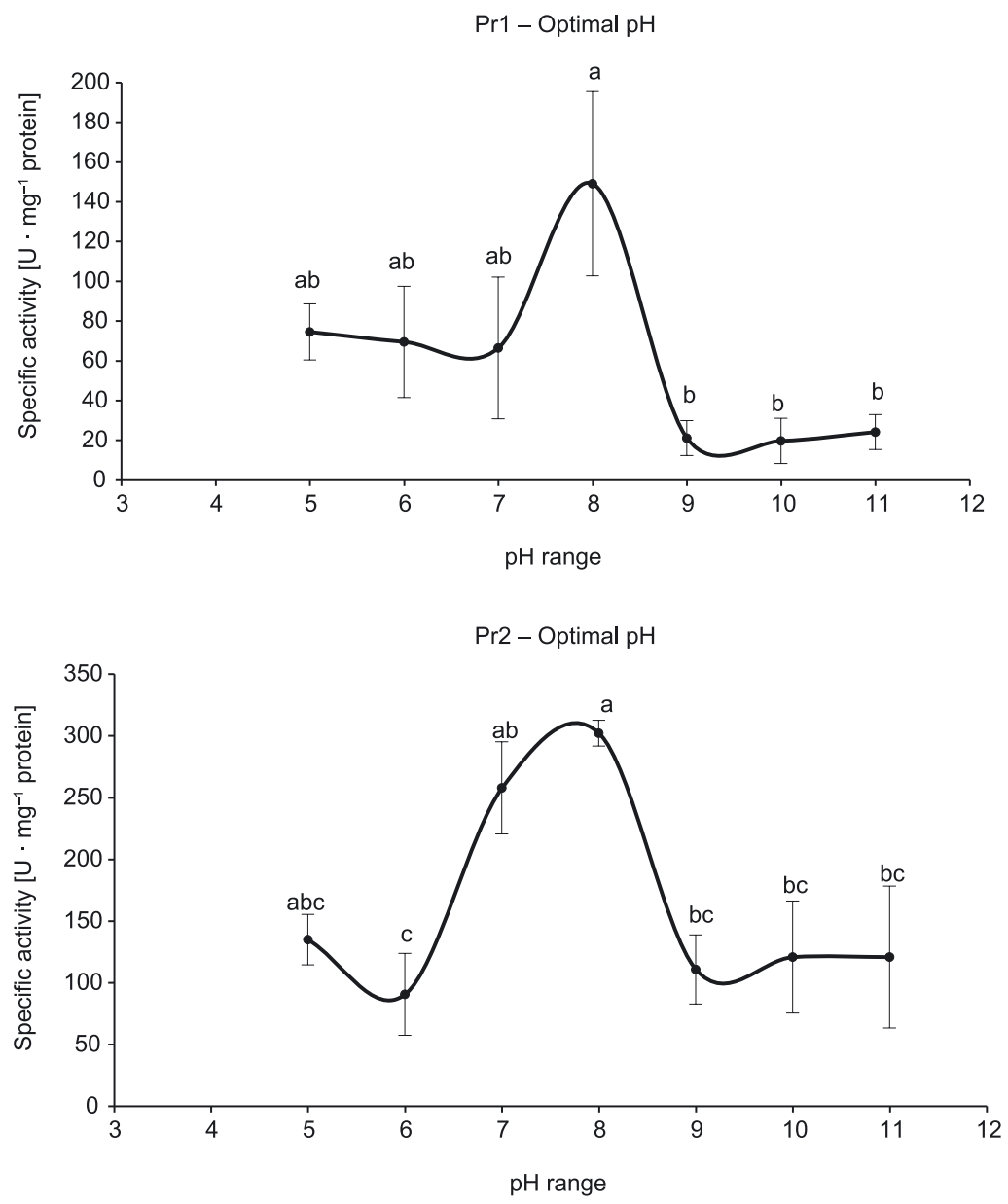

Fig. 4. Optimal pH determination of the purified Pr1 and Pr2 from isolate AM-118 of Beauveria bassiana. Statistical differences have been shown by various letters ( $\mathrm{p} \leq 0.05$; Tukey test)

vival of B. bassiana. Determining the temperature value in which the proteolytic activity of $B$. bassiana reaches its highest value is important when expecting pathogenicity on hosts. Moreover, the $\mathrm{pH}$ of growth media has been shown to have significant effects on entomopathogenic fungi. Hence, the evaluation of this value regarding the pathogenicity of B. bassiana might make it clear whether the enzyme is efficient or not. 

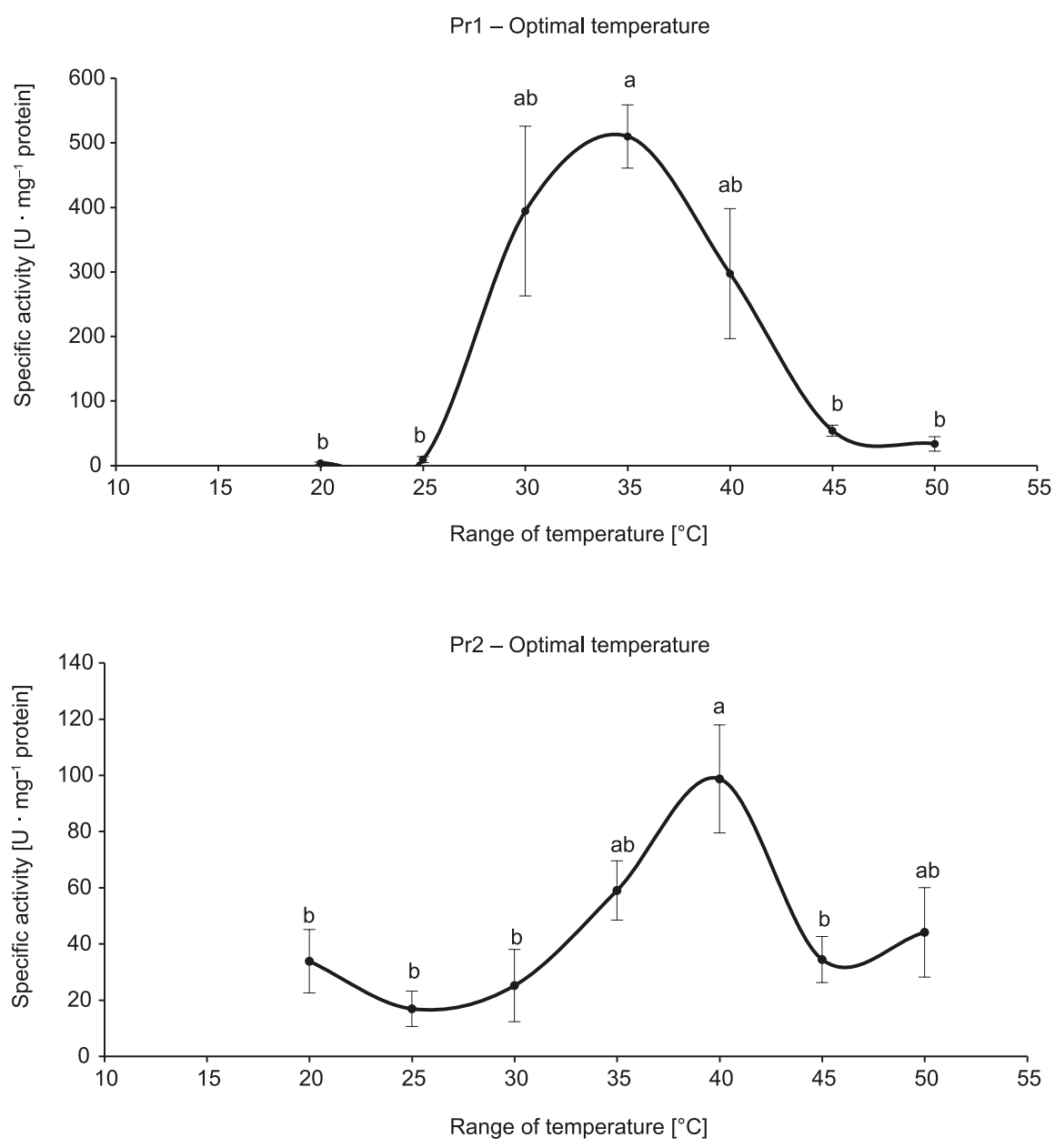

Fig. 5. Optimal temperature determination of the purified Pr1 and Pr2 from isolate AM-118 of Beauveria bassiana. Statistical differences have been shown by various letters ( $\mathrm{p} \leq 0.05$; Tukey test)

Table 3. Inhibition of the purified Pr1 and Pr2 by specific inhibitors

\begin{tabular}{lccc}
\hline \multicolumn{1}{c}{ Inhibitors } & $\begin{array}{c}\text { Concentrations } \\
{[\mathrm{mM}]}\end{array}$ & $\begin{array}{c}\text { Inhibition of Pr1 } \\
{[\%]}\end{array}$ & $\begin{array}{c}\text { Inhibition of Pr2 } \\
{[\%]}\end{array}$ \\
\hline The control & - & $0 \mathrm{~d}$ & $0 \mathrm{~d}$ \\
AEBSF & 5 & $69.44 \mathrm{a}$ & $81 \mathrm{ab}$ \\
TLCK & 5 & $40.26 \mathrm{~b}$ & $90 \mathrm{a}$ \\
TPCK & 5 & $26.38 \mathrm{c}$ & $0 \mathrm{~d}$ \\
Phenanthroline & 5 & $0 \mathrm{~d}$ & $45 \mathrm{~b}$ \\
EDTA & 5 & $0 \mathrm{~d}$ & $46 \mathrm{c}$ \\
\hline
\end{tabular}

AEBSF - 4-(2-aminoethyl) benzenesulfonyl fluoride hydrochloride, TLCK - tosyllysine chloromethyl ketone hydrochloride, TPCK - tosyl phenylalanyl chloromethyl ketone, EDTA - ethylenediamineteraacetic acid ${ }^{*}$ statistical differences have been shown by different letters

\section{Effect of enzyme inhibitors}

Various inhibitors were evaluated for their effects on the purified Pr1 and Pr2 from AM-118. The protease inhibitors: AEBSF, TLCK, and TPCK had significant inhibition on Pr1, but EDTA and phenanthroline showed no effects (Table 3). The trypsin-like Pr2 was inhibited by TLCK, AEBSF, EDTA, and phenanthroline while TPCK showed no inhibition (Table 3). In contrast, Bidochka and Khachatourians (1987) reported no inhibition of B. bassiana proteases by metal-chelating agents, sulfiydryl reagents, trypsin inhibitor, and chymotrypsin inhibitor. Zibaee and Bandani
(2009) found significant inhibition of the enzyme by PMSF and EDTA. These findings revealed that Pr1 contains just amino acids in its active site; mainly serine, histidine, and aspartic acid, but Pr2 may contain metal ions since EDTA, and phenanthroline, inhibit the activity of Pr2.

\section{Conclusions}

We extracted and purified two proteases from an Iranian isolate of B. bassiana. The proteases were novel due to their high molecular weight and their response to specific inhibitors. Knowing the biochemical properties of the en- 
zymes help improve our understanding about the natural degrading of insect integument. Improving the strain selection of entomopathogenic fungi for pest control can then be done. Determination of the enzymatic structure, and identification of the genes responsible for synthesising these enzymes, are necessary for finding the enzymatic capability and interactions with different hosts.

\section{Acknowledgements}

The authors greatly appreciate the valuable comments of Prof. Jan Andrianus Veenstra from Université de Bordeaux 1.

\section{References}

Andreev R., Kutinkova H., Baltas K. 2008. Non-chemical control of some important pests of sweet cherry. Journal of Plant Protection Research 48 (4): 503-508.

Bidochka M.J., Khachatourians G.G. 1987. Purification and properties of an extracellular protease produced by the entomopathogenic fungus, Beauveria bassiana. Applied and Environmental Microbiology 53 (7): 1679-1684.

Bidochka M.J., Meltzer M.J. 2000. Genetic polymorphisms in three subtilisin-like protease isoforms $(\operatorname{Pr} 1 \mathrm{~A}, \operatorname{Pr} 1 \mathrm{~B}$, and Pr1C) from Metarhizium strains. Canadian Journal of Microbiology 46 (12): 1138-1144.

Braga G.U.L., Destefano R.H.R., Messias C.L. 1999. Protease production during growth and autolysis of submerged metarhizium anisopliae cultures. Revista de Microbiologia 30 (2): 107-113.

Castellanos-Moguel J., González-Barajas M., Mier T., Reyes Montes M.R., Aranda E., Toriello C. 2007. Virulence testing and extracellular subtilisin-like (Pr1) and tripsina-like (Pr2) activity during propagule production of Paecilomyces fumosoroseus isolates from whiteflies (Homoptera: Aeyrodidae). Revista Iberoamericana de Micologia 24 (1): 62-68.

Chitgar M.G., Hajizadeh J., Ghadamyari M., Karimi-Malati A., Sharifi M., Hoda H. 2014. Cellular energy allocation in the predatory bug, Andrallus spinidens Fabricius (Hemiptera: Pentatomidae), following sublethal exposure to diazinon, fenitrothion, and chlorpyrifos. Journal of Plant Protection Research 54 (1): 78-84.

Dias B.A., Neves P.M.O.J., Furlaneto-Maia L., Furlaneto M.C. 2008. Cuticle-degrading proteases produced by the entomopathogenic fungus Beuveria bassiana in the presence of coffee berry borer cuticle. Brazilian Journal of Microbiology 39 (2): 301-306.

Fang W., Pava-Ripoli M., Wang S., St. Leger R.J. 2009. Protein kinase A regulates production of virulence determinants by the entomopathogenic fungus, Metarhizium anisopliae. Fungal Genetics and Biology 46 (1): 277-285.

Firouzbakht H., Zibaee A., Hoda H., Sohani M.M. 2015. Virulence determination of Beauveria bassiana isolates on a predatory hemipteran, Andrallus spinidens Fabricius (Hemiptera: Pentatomidae). Acta Phytopathologica et Entomologica Hungarica 50 (1): 115-126.

Frugoni J.A.C. 1957. Tampone universale di Britton e Robinson a forza ionica costante. [Universal Britton and Robinson buffer at constant ionic strength]. Gazzetta Chimica di Italiana 87: 403-407.
Gillespie J.P., Bateman R., Charnley A.K. 1998. Role of cuticledegrding proteases in the virulence of Metarhizium spp. for the desert locust, Schistocerca gregaria. Journal of Invertebrate Pathology 71 (2): 128-137.

Hajji M., Kanoun S., Nasri M., Gharsallah N. 2007. Purification and characterization of an alkaline serine-protease produced by a new isolated Aspergillus clavatus ES1. Process Biochemistry 42 (5): 791-797.

Laemmli U.K. 1970. Cleavage of structural proteins during the assembly of bacteriophage T4. Nature 227: 680-685.

Lakshmi B., Kaur G., Padmini P. 2010. Isolation and purification of cuticle degrading extra cellular proteases from entomopathogenic fungal species of Beauveria bassiana and Metarhium anisopliae. International Journal of Applied Biology and Pharmaceutical Technology 1 (3): 1150-1156.

Larcher G., Bouchara J.P., Annaix V., Symoens F., Chabasse F., Tronchin G. 1992. Purification and characterization of a fibrinogenolytic serine proteinase from Aspergillus fumigatus culture filtrate. FEBS Letter 308 (1): 65-69.

Liu S.Q., Meng Z.H., Yang J.K., Fu Y.K., Zhang K.Q. 2007. Characterizing structural features of cuticle-degrading proteases from fungi by molecular modeling. BMC Structural Biology 7: 33.

Liu W., Xie Y., Xue J., Gao Y., Zhang Y., Zhang X. 2009. Histopathological changes of Ceroplastes japonicus infected by Lecanicillium lecanii. Journal of Inverterbrate Pathology 101 (2): 96-105.

Liu G., Yang L., Fan T., Cong R., Tang Z., Sun W., Meng X., Zhu L. 2006. Purification and characterization of phenoloxidase from crab Charybdis japonica. Fish and Shellfish Immunology 20 (1): 47-57.

Lowry O.H., Rosebrough N.J., Farr A.L., Randall R.J. 1951. Protein measurement with the folin phenol reagent. Journal of Biological Chemistry 193 (1): 265-275.

Pei Y., Ji Z., Yang X., Lu X., Xia Y. 2000. Purification and characterization of cuticle-degrading protease from entomopathogenic fungus, Metarhizium anisopliae. Wei Sheng Wu Xue Bao 40 (3): 306-311.

Pucheta D.M., Macias A.F., Navarro S.R. 2006. De la torre mayra mechanism of action of entomopathogenic fungi. Microbiology 156 (5): 2164-2171.

Ramzi S., Zibaee A. 2014. Biochemical properties of different entomopathogenic fungi and their virulence against Chilo suppressalis (Lepidoptera: Crambidae) larvae. Biocontrol Science and Technology 24 (5): 597-610.

Rodgers P.B. 1989. Potential of biological control organisms as a source of antifungal compounds for agrochemical and pharmaceutical product development. Pesticide Science 27 (2): 155-164.

Safavi S.A. 2010. Isolation, identyfication and pathogenicity assassment of a new isolate of enthomopathogenic fungus, Beauveria bassiana. Journal of Plant Protection Research 50 (2): 158-163.

Samson R.A., Evans H.C., Latg J.P. 1988. Atlas of Entomopathogenic Fungi. Springer, Berlin Heidelberg New York, 187 pp.

Sorkhabi-Abdolmaleki S., Zibaee A., Hoda H., Hosseini R., Fazeli-Dinan M. 2013. Proteolytic compartmentalization and activity in the midgut of Andrallus spinidens Fabricius (Hemiptera: Pentatomidae). Journal of Entomology Acarology Research 45 (1): 33-41. 
St. Leger R.J., Charnley A.K., Cooper R.M. 1986. Cuticle-degrading enzymes of entomopathogenic fungi: synthesis in culture on cuticle. Journal of Inverterbrate Pathology 48 (1): 85-95.

St. Leger R.J., Cooper R.M., Charnley A.K. 1986. Cuticle-degrading enzymes of entomopathogenic fungi: cuticle degradation in vitro by enzymes from entomopathogens. Journal of lnverterbrate Pathology 47 (2): 167-177.

St. Leger R.J., Joshi L., Bidochka M.J., Roberts D.W. 1998. Ambient $\mathrm{pH}$ is a major determinant in the expression of $\mathrm{cu}$ ticle degrading enzymes and hydrophobin by Metarhizium anisopliae. Applied of Environmental Microbiology 64 (2): 709-713.
Tunga R., Shrivastava B., Banerjee R. 2003. Purification and characterization of a protease from solid state cultures of Aspergillus parasiticus. Process Biochemistry 38 (11): 1553-1558.

Zibaee A., Bandani A.R. 2009. Purification and characterization of the cuticle-degrading protease produced by the entomopathogenic fungus, Beauveria bassiana in the presence of sunn pest, Eurygaster integriceps (Hemiptera: Scutelleridae) cuticle. Biocontrol Science Technology 19 (7-8): 797-808.

Zibaee A., Sendi J., Alinia F., Ghadamyari M., Etebari K. 2009. Diazinon resistance in different selected strains of Chilo suppressalis Walker (Lepidoptera: Pyralidae), rice striped stem borer, in the north of Iran. Journal of Economic Entomology 102 (3): 1189-1196. 